\title{
Mortality Due to Suicide in Viet Nam: Time Trend and Related Socio-Economic Status in A Province and Nationwide from 2005 to 2014
}

\author{
Quynh Anh TRAN ${ }^{1}$, Thuong Van NGUYEN ${ }^{2}$, Thien Cong LE ${ }^{3}$ and Ngoan Tran LE ${ }^{4,5 *}$ \\ ${ }^{1}$ Department of Environmental Health, Hanoi Medical University, Hanoi, Viet Nam \\ ${ }^{2} \mathrm{Nghe}$ An Provincial Health Department, Nghe An, Viet Nam \\ ${ }^{3}$ Department of Mental Health, Hanoi Medical University, Hanoi, Viet Nam \\ ${ }^{4}$ Department of Occupational Health, Hanoi Medical University, Hanoi, Viet Nam \\ ${ }^{5}$ Department of Public Health, International University of Health and Welfare, Japan
}

ORCID: Ngoan Tran Le: 0000-0001-7862-492X

*Corresponding author: Ngoan Tran LE, Department of Occupational Health, Hanoi Medical University, Hanoi, Viet Nam

ARTICLE INFO

Received: 慧 December 05, 2021

Published: 幽 December 10, 2021

Citation: Quynh Anh TRAN, Thuong Van NGUYEN, Thien Cong LE, Ngoan Tran LE. Mortality Due to Suicide in Viet Nam: Time Trend and Related Socio-Economic Status in A Province and Nationwide from 2005 to 2014. Biomed J Sci \& Tech Res 40(3)-2021. BJSTR. MS.ID.006459.

\begin{abstract}
Time trend and the association between social-economics status and suicide (ICD10: X60-X84) in the Nghe An province during 2005-2014 and all 64 provinces/cities in Vietnam in 2005 were examined by using the database of yearly population-based mortality registration. Nine groups were divided from the highest to lowest socialeconomic developments. Mortality rates ratio and 95\% confidence interval (MRR and $95 \% \mathrm{CI}$ ) and age-adjusted mortality rate (ASR) per 100,000 were calculated. Results showed that there were 1,695 deaths in the Nghe An during 2005-2014 and 3,808 deaths from suicide in 2005 in the whole country. Overall mortality rate (ASR) per 100,000 was 5.53 , men 7.89 , and women 3.53 , giving a men-to-women ratio of 2.24 . There was a significantly increased risk of suicide in the disadvantaged region of the Northwest vs the Hanoi and Ho Chi Minh cities, MRR=6.08 and 95\%CI: 5.07-7.30, men and women combined. The socioeconomic condition needs to be taken into account in prevention programs for suicide in Vietnam.
\end{abstract}

Keywords: Mental-Health; Suicide; Mortality; Equity, Viet Nam

\section{Introduction}

Suicide was defined as a self-imposed death where people kill their selves deliberately and voluntarily (Pilgrim, 2014). Suicide has been acknowledged as a significant social and public health problem with approximately 800,000 people dying due to suicide every year. Suicide accounted for $1.4 \%$ of all deaths worldwide, making it the eighteenth leading cause of death in 2016. WHO reported that $79 \%$ of suicides occurred in low- and middle-income countries in 2016 WHO [1]. Social inequality has been recognized as a significant risk factor for suicidal behaviors in both developed and developing countries. A previous study indicated that arealevel socioeconomic disadvantage increased the risk of attempting suicide among adolescents in the US Yildiz, et al. [2]. A systematic review from 14 different European countries found that there was a significant association between socioeconomic disadvantage and suicidal behavior from 2005 to 2015 Cairns, et al. [3]. Another review revealed a constituent trend at the individual level indicating that poverty is linked with suicidal ideations and behaviors among people living in low- and middle-income countries Iemmi, et al. [4]. 
Vietnam is among developing countries located in South East Asia having drastic changes in socio-economic conditions in the past decade.

The Vietnam average population has reached 94,666 thousand persons in 2018. The gross domestic product of Vietnam has increased from 1,064 USD per capita in 2011 to 2,389 USD per capita in 2017 General Statistics Office of Vietnam [5]. The crude death rate of Vietnam was 6.8 per 1000 people in 2015 Ministry of
Health [6]. However, the mortality due to suicide and related factors are unknown in Vietnam. As suicide is preventable, understanding the changes, consequences and the impact of socioeconomic status is vital to provide evidence-based recommendations. This study aims to examine the changes in mortality due to suicide from 2005 to 2014 in a province and the link between socioeconomic status and mortality due to suicide at the provincial level and national level (Figure 1).

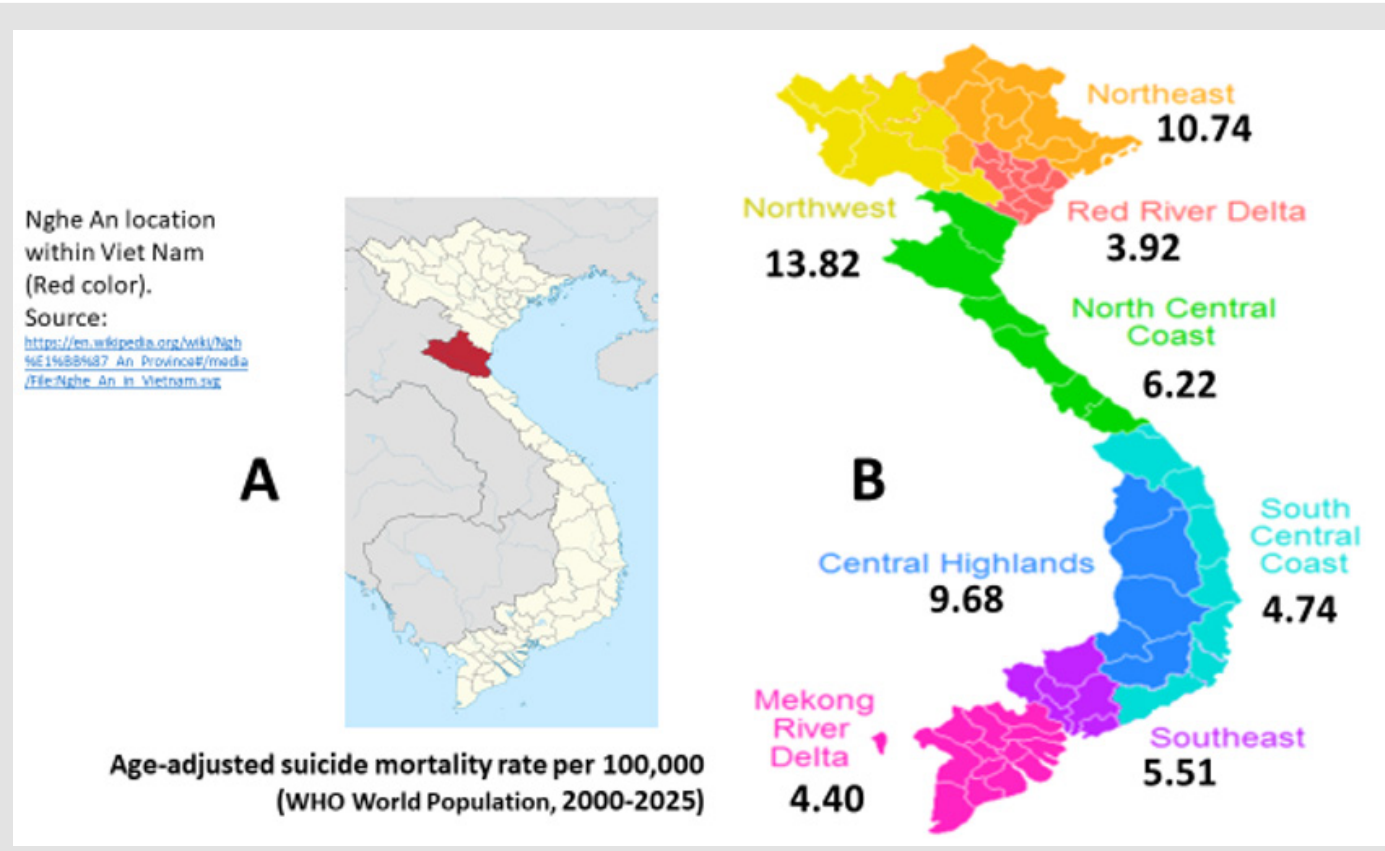

Figure 1:

(A) Nghe An location within Viet Nam and

(B) Age-adjusted suicide mortality rate per 100,000 by social-economics status.

\section{Methods}

\section{Study Design}

This is a descriptive study of the registered death case series due to suicide (ICD-10: X60-X84) in the Nghe an province during 2005-2014 (1,695 cases) and nationwide in 2005 (3,808 cases).

\section{Study Setting}

We annually collected data of population by sex and causes of death to suicide for the present study through the A6 mortality registration system. In this study, we selected the Nghe an province to collect data at the provincial level because the database was available for ten year-period from 2005 to 2014. The Nghe an province is located in the North Central Coast with an average population of $3,080,000$ people in 2015 , ranked as the fourth most populous province in the country General Statistics Office of Vietnam [5]. The number of deaths collected in the Nghe an province covered the period of ten years from 2005-2014. Data at the national level were collected across all 64 provinces/cities in 2005. This year, Viet Nam had 10,769 commune health stations (CHS) of 671 districts within all 64 provinces/cities. There was $67.8 \%$ of all 10,769 -commune health stations employed physicians. Therefore, this existing advantage official grass-root health system network provided a favorable environment to report the cause of death in general as well as suicide in particular for the present study. The average population number of each commune in Viet Nam was about 7,617 residents. According to the estimated crude death rate of 500 per 100,000 per year, the estimated number of deaths per month at one commune was three cases. Therefore, the head of the commune health station can registry into the A6 book actively as the requirement by the ministry of health Le, et al. [7].

\section{Data Collection}

In Vietnam, the national mortality registration system, officially named A6 mortality registration, established by the Ministry of Health in 1992, recorded all deaths from commune-level by each 
CHS. We annually collected data through A6 mortality registration from 2005-2014 for the Nghe An province and the whole year of 2005 for all 64 provinces and cities. The designated data collection form was yearly sent to 10,769 CHSs of 671 districts within all 64 provinces/cities in 2005. The heads of CHSs were data collectors who recorded all dead cases including death due to suicide including five variables of name, age, sex, date of death, and cause of death. These variables were presented in the data collection form named "Mortality registration". A guideline of mortality registration and the causes of death including the underlying cause, immediate cause, and a contributing cause of death recommended by WHO was prepared WHO [8]. The printed data collection form with a guideline, each CHS receiving at least one set, was sent to the directors of 64 provinces/cities Health Department with a request letter of data collection. In 2005, we had received 10,184 completed forms of "Mortality registration" (94.6\% of all 10,769 CHSs nationwide). Data was inputted into an Excel file for 671 districts within all 64 provinces/cities in 2005. The cause of all deaths was code ICD-10 and suicide (ICD-10: X60-X84) for the present study.

\section{Data Quality Validation}

For data validation, after obtaining the mortality database, all causes of death were determined by using the WHO Verbal Autopsy questionnaire that was referred to as "the goal standard" WHO [8]. In Nghe An province, data quality was validated for completeness and accuracy of mortality registration in a District for 1,581 deaths occurring in 2014. For all causes including suicide cases, the estimated completeness was excellent reaching as high as $97 \%$ Thuong NV, et al. [9]. The estimated Kappa was excellent for the group of injury including suicide, reaching as high as $81 \%$; the reference group was Verbal Autopsy's database (unpublished data).

\section{Data Analysis and Statistical Methods}

All obtained data about deaths as well as demographic information was computed using Excel software. We checked for a health event and the cause of death and code following ICD-10. The Excel data were exported to STATA 10.0 for analysis. Mortality rates ratios and 95\% confidence interval (MRR, 95\% CI) were estimated by performing logistic regression analysis, adjusting for sex, age groups $(0-9,10-19,20-29,30-39,40-49,50-59,60-69,70-79$, and
$80+$ ), the proportion of unknown underlying cause of death (ICD10: R01-R99) and all-cause mortality rates. For the time trend during the period 2005-2014, we divided it into five sub periods of two years (2005-2006: reference group, 2007-2008, 20092010, 2011-2012, and 2013-2014). For socioeconomic status, we divided 64 provinces/cities into nine regions from the highest to lowest social-economic developments. Region 1 (reference group) includes the two most populous cities (Hanoi and Hochiminh City). Regions from 2-9 include Red River Delta, Mekong River Delta, South Central Coast, Southeast, North Central Coast, Central Highlands, Northeast, and Northwest.

\section{Ethical Approval}

The research protocol was approved by the Ethics Committee of Hanoi Medical University on 25 November 2008.

\section{Results}

(Table 1) presents data for the Nghe an province. During the ten years of 2005-2014, the system recorded 1,150 dead cases among males, 545 cases among females, and a total of 1,695 deaths due to suicide. After age-adjusted, the suicidal mortality rate per 100,000 for males ranged from 7.40 (in the years of 2011-2012) to 8.70 (in the years of 2007-2008); for females ranged from 3.38 (in the years of 2013-2014) to 4.36 (in the years of 2009-2010). When compared to the period 2005-2006, the risk of death from suicide during 2013-2014 was not significantly changed, MRR, 95\%CI: 0.95 (0.82, 1.12), $\mathrm{p}=0.56$. Per increments time-period MRR (95\%CI): $0.98(0.95,1.01), p$ for trend $=0.23$. (Table 2$)$ shows the number of deaths due to suicide for the whole country in 2005 in total and by sex. The system recorded 3,808 dead cases of which $65.0 \%$ accounted for males. The suicidal mortality rate per 100,000 among males (7.89) was two times higher than females (3.53), giving a men-to-women ratio of 2.24 (Table 3) presents the number of deaths due to suicide, mortality rate ratios, and $95 \%$ confidence interval by nine socioeconomic regions throughout the country in 2005. Nine regions were ordered from the highest to the lowest socio-economic conditions. It is significant that the lower level of socio-economic conditions, the higher the mortality rate ratios. This trend was similar for males and females.

Table 1: Number, crude and age-standardized rate per 100,000 by sex and time during 2005-2014 in the Nghe An province.

\begin{tabular}{|c|c|c|c|c|c|c|c|c|c|c|c|c|c|c|}
\hline \multirow[b]{2}{*}{ Year period } & \multicolumn{4}{|c|}{ Men } & \multicolumn{4}{|c|}{ Women } & \multicolumn{4}{|c|}{ Total } & \multirow[b]{2}{*}{ MRR (95\%CI) } & \multirow[b]{2}{*}{$\mathrm{P}$} \\
\hline & Death & $\%$ & Crude & ASR & Death & $\%$ & Crude & ASR & Death & $\%$ & Crude & ASR & & \\
\hline $2005-2006$ & 200 & 1.50 & 7.90 & 8.17 & 94 & 1.00 & 3.60 & 3.60 & 294 & 1.29 & 5.75 & 5.80 & 1.00 (reference) & \\
\hline $2007-2008$ & 231 & 1.50 & 8.70 & 8.97 & 95 & 0.90 & 3.50 & 3.40 & 326 & 1.30 & 6.10 & 6.10 & $1.06(0.90,1.24)$ & 0.48 \\
\hline $2009-2010$ & 251 & 1.50 & 8.50 & 8.90 & 134 & 1.10 & 4.50 & 4.36 & 385 & 1.30 & 6.50 & 6.51 & $1.13(0.97,1.31)$ & 0.12 \\
\hline 2011-2012 & 230 & 1.20 & 7.40 & 7.71 & 113 & 0.90 & 3.60 & 3.60 & 343 & 1.10 & 5.50 & 5.58 & $0.96(0.82,1.12)$ & 0.59 \\
\hline $2013-2014$ & 238 & 1.30 & 7.60 & 7.83 & 109 & 0.80 & 3.40 & 3.38 & 347 & 1.10 & 5.50 & 5.53 & $0.95(0.82,1.12)$ & 0.56 \\
\hline $2005-2014$ & 1,150 & 1.40 & 8.00 & 8.30 & 545 & 1.00 & 3.74 & 3.67 & 1,695 & 1.20 & 5.85 & 5.89 & $0.98(0.95,1.01) \&$ & 0.23 \\
\hline
\end{tabular}

Note: ASR: Reference to the WHO World Standard (2000-2025) \& per increments time-period MRR (95\% CI): 0.98 (0.95, 1.01), p for trend $=0.23$. 
Table 2: Number, crude and age-standardized rate per 100,000 by sex in all 64 provinces/cities in 2005.

\begin{tabular}{|c|c|c|c|c|}
\hline \multirow{2}{*}{ Sex } & \multirow{2}{*}{ Death } & \multirow{2}{*}{ Person-year } & \multicolumn{2}{|c|}{ Rate per 100,000 } \\
\cline { 3 - 5 } & & & Crude & ASR \\
\hline Men & 2,485 & $37,596,168$ & 6.61 & 7.89 \\
\hline Women & 1,323 & $39,130,705$ & 3.38 & 3.53 \\
\hline Total & 3,808 & $76,726,873$ & 4.96 & 5.53 \\
\hline
\end{tabular}

Note: ASR: Reference to the WHO World Standard (2000-2025)

Table 3: Risk of suicide by social-economic status in 2005.

\begin{tabular}{|c|c|c|c|c|c|c|c|}
\hline \multirow{2}{*}{ No } & \multirow{2}{*}{ Region } & \multicolumn{2}{|c|}{ Both sexes } & \multicolumn{2}{c|}{ Men } & \multicolumn{2}{c|}{ Women } \\
\cline { 3 - 8 } & & Deaths & MMR (95\%CI)\$ & Deaths & MMR (95\%CI)\# & Deaths & MMR (95\%CI)\# \\
\hline 1 & Cities* & 210 & 1.00 (Reference) & 160 & 1.00 (Reference) & 50 & $1.00($ Reference) \\
\hline 2 & Red River Delta & 519 & $1.57(1.34,1.85)$ & 340 & $1.36(1.12,1.64)$ & 179 & $2.28(1.66,3.12)$ \\
\hline 3 & Mekong River Delta & 586 & $1.87(1.59,2.19)$ & 406 & $1.70(1.42,2.05)$ & 180 & $2.38(1.74,3.25)$ \\
\hline 4 & South Central Coast & 275 & $1.93(1.61,2.30)$ & 173 & $1.60(1.29,1.99)$ & 102 & $2.96(2.11,4.15)$ \\
\hline 5 & Southeast & 319 & $2.20(1.85,2.62)$ & 218 & $2.22(1.63,2.45)$ & 101 & $2.85(2.03,4.00)$ \\
\hline 6 & North Central Coast & 521 & $2.40(2.05,2.82)$ & 328 & $1.99(1.65,2.40)$ & 193 & $3.72(2.73,5.08)$ \\
\hline 7 & Central highlands & 275 & $3.96(3.31,4.74)$ & 179 & $3.43(2.77,4.24)$ & 96 & $5.62(3.99,7.91)$ \\
\hline 8 & Northeast & 842 & $4.59(3.95,5.34)$ & 534 & $3.83(3.21,4.57)$ & 308 & $6.98(5.18,9.41)$ \\
\hline 9 & Northwest & 261 & $6.08(5.07,7.30)$ & 147 & $4.56(3.65,5.71)$ & 114 & $10.82(7.75,15.10)$ \\
\hline
\end{tabular}

Note: *Hanoi and Ho Chi Minh cities (The reference group)

MMR (95\% CI): Mortality rates ratio and 95\% confidence interval

$\$$ adjusted for age and sex; \# adjusted for age

Table 4: Percent distribution and age-specific suicide mortality per 100,000 by sex and age groups, deaths reported from 64 provinces / cities in 2005.

\begin{tabular}{|c|c|c|c|c|c|c|c|c|c|}
\hline & \multicolumn{3}{|c|}{ Men } & \multicolumn{3}{c|}{ Tomen } & \multicolumn{2}{c|}{ Total } \\
\hline Age group & Deaths & $\begin{array}{c}\text { Rate per } \\
\mathbf{1 0 0 , 0 0 0}\end{array}$ & $\mathbf{\%}$ & Deaths & $\begin{array}{c}\text { Rate per } \\
\mathbf{1 0 0 , 0 0 0}\end{array}$ & $\%$ & Deaths & $\begin{array}{c}\text { Rate per } \\
100,000\end{array}$ & \begin{tabular}{c} 
\% \\
\hline $1-9$
\end{tabular} \\
\hline $10-19$ & 247 & 2.82 & 9.94 & 252 & 2.96 & 19.05 & 499 & 2.89 & 13.10 \\
\hline $20-29$ & 679 & 10.42 & 27.32 & 396 & 5.82 & 29.93 & 1,075 & 8.07 & 28.23 \\
\hline $30-39$ & 581 & 10.21 & 23.38 & 241 & 4.06 & 18.22 & 822 & 7.07 & 21.59 \\
\hline $40-49$ & 478 & 13.17 & 19.24 & 182 & 4.48 & 13.76 & 660 & 8.59 & 17.33 \\
\hline $50-59$ & 222 & 12.57 & 8.93 & 91 & 4.10 & 6.88 & 313 & 7.86 & 8.22 \\
\hline $60-69$ & 138 & 9.02 & 5.55 & 74 & 3.81 & 5.59 & 212 & 6.10 & 5.57 \\
\hline $70-79$ & 96 & 11.74 & 3.86 & 51 & 4.11 & 3.85 & 147 & 7.14 & 3.86 \\
\hline $80+$ & 41 & 17.93 & 1.65 & 32 & 6.59 & 2.42 & 73 & 10.22 & 1.92 \\
\hline Total & 2,485 & 6.61 & 100 & 1,323 & 3.38 & 100 & 3,808 & 4.96 & 100 \\
\hline
\end{tabular}

The lowest MMR was found in the Red River Delta (excluding Hanoi) (MMR=1.57; 95\%CI=1.34-1.85 in total after being adjusted for age and sex; $M M R=1.36$; $95 \% \mathrm{CI}=1.12-1.64$ for males; $\mathrm{MMR}=2.28$; 95\% CI=1.66-3.12 for females; age-adjusted for males and females). The highest MMR was observed in the Northwest (MMR=6.08; 95\% $\mathrm{CI}=5.07-7.30$ in total after being adjusted for age and sex; $\mathrm{MMR}=4.56$; $95 \% \mathrm{CI}=3.65-5.71$ for males; $\mathrm{MMR}=10.82 ; 95 \% \mathrm{CI}=7.75$ 15.10 for females; age-adjusted for males and females). Compared to the region with the highest level of socio-economic condition, the individual living in the lowest region had an increased risk of 6.08 times higher to die by suicide. A similar risk was 4.56 times higher for males and 10.82 for females. (Table 4) presents the number of deaths due to suicide and the mortality rate per 100,000 people by age group. The highest mortality rate was found in the age group of 80 and over (10.22 in total, 17.93 for males, and 6.59 for females). The lowest mortality rate was found in the age group of 10-19 (2.89 
in total, 2.82 for males, and 2.96 for females). No dead cases due to suicide were recorded for the age group of 1-9. We did not find a particular change in the suicide mortality rate by age group. The men-to-women ratio remains different at all age groups, except a group of 10-19. Among working-aged from 20 to 59, there were 2,870 deaths due to suicide or $75 \%$ of 3,808 suicide cases occurred at the working ages.

\section{Discussion}

The main findings have shown a whole country's suicide status in 2005 and the fatal health event has not been changed during ten year-period from 2005 to 2014 in the Nghe An province, pointing out of suicide being a neglected serious mental health problem. Social determinants of low socioeconomic status or poverty were significantly increased the risk of suicide at disadvantage areas. The other important findings were suicide occurred among senior citizens and about three-fourth of total cases of premature death at working ages. To the best of our knowledge, this is the first study in Vietnam examining the mortality rate due to suicide and the association between suicide and socio-economic status nationwide. The sources of data are reliable because they were collected from the national registration system. The mortality rates are adjusted by age and sex as appropriate. The most important findings from our study are that socio-economic status was negatively associated with suicide mortality rate ratios. Compared to the region with the highest level of socio-economic condition, the individual living in the lowest region had a significantly increased risk of suicide. This finding is in line with previous studies that reported that socioeconomic disadvantage increased the risk of suicide at both the individual level and area-level in many countries Cairns, et al. [2-4].

The suicide dead cases for the whole of Vietnam was 3,803 with an overall mortality rate (ASR) per 100,000 was 5.53 , men 7.89 and women 3.53 , giving men-to-women ratio 2.24 . This mortality rate in Vietnam is much lower than the suicide death rate reported in India (22.0 cases per 100,000) Patel, et al. [10]. The suicide death rate was higher among males that were consistent with findings from other studies Patel, et al. [10,2,4]. We found a significant number of 2,870 deaths due to suicide $(75 \%)$ occurred during the working ages. This finding raises a concern about adult mental health care in Vietnam and further studies on the causes and risk factors at different occupations. Research worldwide supposed that low socioeconomic conditions, especially unemployment are strongly related to suicidal mortality, and poor psychosocial working conditions associated with suicide Guseva Canu, et al. [1113]. Suicidal behaviors include the complex process of thoughts, planning, and attempts. Social support plays an important role in preventing suicide from the beginning of suicidal ideation.
Help-seeking behaviors are reported to be correlated with the effectiveness of preventing suicide among working ages Ko, et al. [14].

In Vietnam, researches focus on suicide in the young population more than in the elderly. The highest suicide mortality accounted for the age group from 80 years old in our study suggested that health care for the elderly in Vietnam needs to be studied further. Sociodemographic including social isolation, becoming a widow/ widower, bereavement, health conditions, and mental health problems such as dementia are recognized as risk factors of suicidal behavior in older adults in many countries Conejero, et al. [15]. Along with economic development, Vietnam is facing with challenges of an aging population and social disparities that may increase the prevalence of suicidal behaviors in older people. One of the leading causes of suicide is depression and mental illnesses. One possible explanation for the high suicide mortality at low socioeconomic regions may be that mental health problems have been neglected in these regions with the lack of mental health care and mental health education. Although Vietnam has a good healthcare system from the grassroots level as commune health stations, mental health services are not available and accessible for local people in disadvantaged regions. Individuals with mental illnesses or individuals with suicidal behavior can place a significant financial and social burden on communities. Therefore, understanding mental health problems among different age groups or different socioeconomic conditions is necessary to propose comprehensive preventive programs.

Despite these findings, it is important to note some limitations associated with the study. There were potential under-reported deaths due to suicide because people want to hide this sensitive health event and most of the suicide cases were not admitted into hospitals. The other limitation was that there was no available full information on causes of suicide that occurred among the working ages and senior citizens. Our research project is continuing and these limitations will be fixed in the next updated study.

\section{Conclusion}

The findings suggest that there was a big gap in mental health care between social-economic status and input support from domestic and international aids to avoid preventable suicide in disadvantaged regions in Viet Nam is highly needed.

\section{Acknowledgment}

The study was partly supported by the Asian Development Bank (ADB), Regional Pooled Fund of the Greater Mekong SubRegion Communicable Diseases Control Project (GMS CDC Project); an AusAID Research and Development Grant. 


\section{References}

1. (2020) WHO (nd). Suicide data.

2. Yildiz M, Demirhan E, Gurbuz S (2019) Contextual Socioeconomic Disadvantage and Adolescent Suicide Attempts: A Multilevel Investigation. Journal of Youth and Adolescence 48(4): 802-814.

3. Cairns JM, Graham E, Bambra C (2017) Area-level socioeconomic disadvantage and suicidal behavior in Europe: A systematic review. Social Science \& Medicine 192: 102-111.

4. Iemmi V, Bantjes J, Coast E, Channer K, Leone T, et al. (2016) Suicide and poverty in low-income and middle-income countries: A systematic review. The Lancet Psychiatry 3(8): 774-783.

5. (2018) General Statistics Office of Vietnam. Statistical data.

6. (2017) Ministry of Health. Health Statistic Year Book 2016.

7. Le TN, Nguyen TL, Lai TMH (2007) Cancer Mortality Pattern in Viet Nam. Asian Pacific Journal of Cancer Prevention 8(4): 535-538.

8. (2007) WHO. Verbal autopsy standards: Ascertaining and attributing causes of death. Geneva, Switzerland.

9. Thuong NV, Minh LQ Stevenson M, Linh LT, Ngoan LT (2017) Evaluation of a Population-based Intervention to Improve the Vietnamese Mortality Reporting System. Southeast-Asian J of Sciences 5(2): 194-204.

\section{ISSN: 2574-1241}

DOI: $10.26717 /$ BJSTR.2021.40.006459

Ngoan Tran LE. Biomed J Sci \& Tech Res

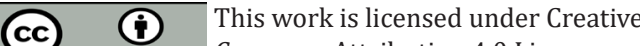

Submission Link: https://biomedres.us/submit-manuscript.php
10. Patel V, Ramasundarahettige C, Vijayakumar L, Thakur JS, Gajalakshmi V, et al. (2012) Suicide mortality in India: A nationally representative survey. Lancet (London, England) 379(9834): 2343-2351.

11. Guseva Canu I, Bovio N, Mediouni Z, Bochud M, Wild P, et al. (2019) Suicide mortality follow-up of the Swiss National Cohort (1990-2014): Sex-specific risk estimates by occupational socio-economic group in the working-age population. Social Psychiatry and Psychiatric Epidemiology 54(12): 1483-1495.

12. Fountoulakis KN (2020) Suicides in Greece before and during the period of austerity by sex and age group: Relationship to unemployment and economic variables. Journal of Affective Disorders 260: 174-182.

13. Rivera B, Casal B, Currais L (2017) Crisis, suicide, and labor productivity losses in Spain. The European Journal of Health Economics 18(1): 83-96.

14. Ko J, Frey JJ, Harrington D (2019) Preventing Suicide Among WorkingAge Adults: The Correlates of Help-Seeking Behavior. Inquiry: A Journal of Medical Care Organization, Provision, and Financing 56: 46958019850979-46958019850979.

15. Conejero I, Olié E, Courtet P, Calati R (2018) Suicide in older adults: Current perspectives. Clinical Interventions in Aging 13: 691-699.

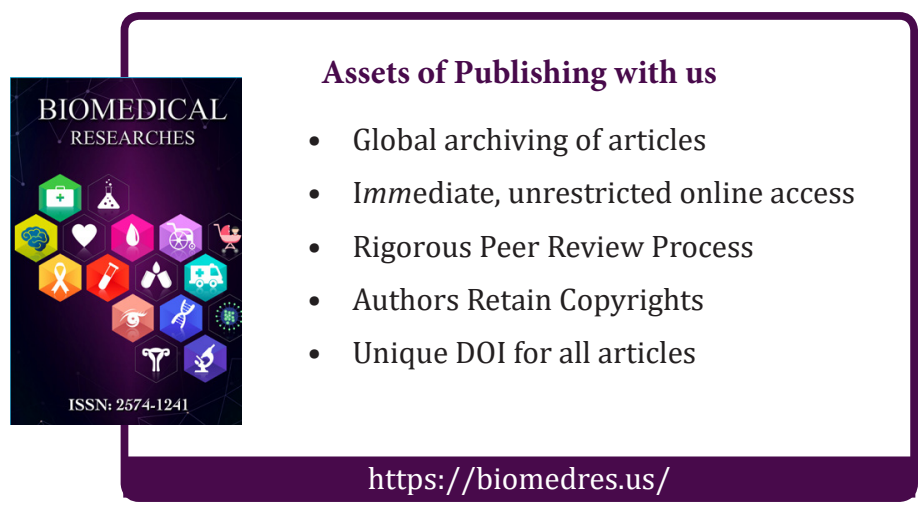

